\title{
EDITORIAL
}

\section{Reflecting on the current status and focus of e-learning research}

This special issue contains six articles from international leading lights in the field of e-learning, so it provides a valuable snapshot of current thinking and research activities. It had arisen out of keynote and theme speaker presentations at two key e-learning conferences last year: ALT-C 2004 'Blue Skies and Pragmatism-learning technologies for the next decade', which was held in Exeter; and the Colston Symposium entitled 'The Evolution of Learning and Web Technologies: survival of the fittest?', which was held in Bristol.

It is interesting that, despite the different focus of each of the papers in this issue, there are a number of common themes that cut across them, which are useful indicators of current thinking in this area and encouragingly suggesting that our area of research is starting to mature.

The papers reflect on some of the key issues involved in current e-learning research and development: quality assurance, repurposing of learning objects, researching perceptions about e-learning and associated methodological issues, open courseware initiatives and mechanisms for implementing strategic change.

Ron Oliver, from Edith Cowan University, Australia, starts the issue off with an insightful and reflective piece on the role of quality assurance in e-learning. $\mathrm{He}$ addresses the question: 'What are the necessary conditions for e-learning and can these conditions guarantee that e-learning will be successful?'

Cathy Gunn and colleagues from Auckland University outline what they describe as a 'sustainable and participative approach to reuse that involves repurposing learning objects for different discipline areas'. In particular, they argue that 'teachers need to develop new and contextually appropriate instructional strategies for learnercentric design models'. This is a viewpoint that has gained wide-scale acceptance in recent years, and which interestingly also aligns well with current directions and thinking in underpinning learning theories - with a shift from individualistically focused approaches to learning to those based on constructivist and socially situated approaches.

In Gilly Salmons' paper the focus is on institutional wide implementation, and in particular the development of appropriate strategic frameworks to support this. She reflects on the current status of e-learning, using the metaphor of flight-suggesting that in terms of e-learning, 'the introduction of ICT into the world of learning and teaching in universities is now in transition from "flapping" to mass take off'. She goes on to describe the approach adopted at Leicester University, which consists of a four- 
quadrant framework that takes account of integration of both mainstream and peripheral technologies. It will be interesting in due course to see a follow-up paper on the effectiveness of this approach as all institutions are struggling with addressing this central issue and ways to implement e-learning effectively, strategically and on a wider scale.

The fourth paper by de Vries et al., from The Netherlands, follows on from Rob Koper's themed presentation at ALT-C 2004. It represents a detailed empirical study that attempts to identify the critical factors associated with providing support for students in an e-learning environment. They used a Nominal Group Technique to gather the data and categorised these factors into content-related, process-related and product-related support activities. This also raises interesting methodological issues about the ways in which we categorise and code data and the meaning we can subsequently derive from these approaches.

The final two articles are discussion pieces, which provide a snapshot of current elearning developments and reflection on future directions. Sarah Porter, from the Joint Information Systems Committee, reflects on the papers presented at ALT-C 2004 that were under the technical infrastructure and new technology strands of the conference. She states that "there is a highly complex set of relationships between "innovative", "risky" or "blue skies" technology and its effective use in supporting practitioners or "pragmatism", and goes on to pose a series of questions: What should be the relationship between technology and practice? Should technology stimulate innovation in practice or should technology support practice? Or is it able to do both? At what point should innovation become 'embedded' into practice and how can this be achieved? The discussion piece then reflects on the extent to which these questions were addressed in the papers at the conference. Vijay Kumar's discussion piece is based on his keynote presentation at ALT-C 2004. His papers describes the background to the much publicised MIT Open Courseware initiative and highlights some of the educational opportunity presented by MIT's current IT-enabled educational agenda and related initiatives, along with their strategic underpinnings and implications. It examines how these ambitious programmes achieve a vision characterised by an abundance of sustainable, transformative educational opportunities, not merely pervasive technology.

Reading through the six articles I was struck by how they demonstrate the way in which e-learning research and development has begun to mature, and in particular how, despite focusing on different specific aspects of research, a number of common themes emerge. For example, the role of learning objects and the purpose of reuse cuts across a number of the papers (Oliver, Gunn and Porter, for example), and effective strategic frameworks is clearly a focus for Oliver, Salmon and Kumar. The move towards more of a component-based approach to development is evidently present in both Porter and Kumar's papers. I hope, like me, you will enjoy reading these papers and find them stimulating in terms of providing an understanding of current e-learning research developments and reflection on what these mean in terms of future directions for our area. 